\title{
Transforming Society Through Pilot and Demonstration Projects
}

\begin{abstract}
This chapter introduces pilot and demonstration projects as a key mode of innovation within contemporary energy and mobility transitions. It argues that such projects are important political sites for the production of future socio-technical order. The politics of such projects are contested: on the one hand, they have been argued to remove political agency from deliberative fora in favour of private decisions, on the other hand they have been argued to constitute new democratic opportunities. This chapter situates a discussion on these issues within Science and Technology Studies (STS). The chapter further discusses the relationship between STS and some of the currently dominating approaches to sustainability transitions and argues how STS can bring new insights to the study of energy transitions and societal change. The chapter also provides basic insights into some key social and technical aspects of current energy and mobility transitions.
\end{abstract}

Keywords Pilot projects $\bullet$ Energy transitions $\bullet$ Sustainability transitions - STS • Participation • Politics

\section{INTRODUCTION}

In 1882, Thomas Edison unveiled a spectacular public display by electrically illuminating the offices of Drexel, Morgan and Company in the financial district of New York. Powered by the Pearl Street station in 
Manhattan, this represented a challenge to what has been described as a "formidable rival", a gas industry and infrastructure that was not only economically and technically dominant, but an integral aspect of how the city functioned. In the words of Hargadon and Douglas, "gas was inextricably woven into the city's physical and institutional environments" (2001, p. 484). Nevertheless, incandescent light bulbs replaced gas in no more than 15 years, in what truly was a transition in the way New York was illuminated.

Many scholars have since noted that this success cannot be attributed to any single invention, and especially not the one made by Edison. Electric light bulbs had been successfully displayed decades before the 1882 events, and Edison was neither the inventor of the generator, nor the distribution system. The novelty in what Edison and his company did in New York could primarily be found in the systemic traits of their efforts, which combined power generation distributed through an electricity grid and in turn used by a small set of real-life users (see e.g. Hughes 1993; Hargadon and Douglas 2001; Geels 2010a). Hence, Edison illustrated real-world application for a new type of socio-technical configuration which has later been described as "providing the model for subsequent development of the technology" (Hargadon and Douglas 2001, p. 482).

Presently, we are faced with a situation where the need to transition away from large technical systems based on fossil fuels has become evident. In practice this means that a shift is needed away from the very coal power stations introduced by Edison, as well as the many technologies that provide heating, cooling, light, digital images, storage, industry, transport and all the other services we take for granted in late modernity that are enabled by the burning of fossil fuels. These challenges by far exceed those of replacing the gas system for illuminating New York in the 1880s and 1890s. The International Panel on Climate Change (Rogelj et al. 2018) highlights that keeping within the boundaries of 1.5 or 2.0-degree global warming will require a rapid transition of both supply and demand aspects of global energy systems by 2050. In practice, this means working to transform both energy production and energy use-and that this must happen quickly.

The grand challenges facing the energy- and sustainability transitions that need to happen are the core interest of this book. While the IPCC mainly operates macroscopically to illustrate how energy transitions need 
to pan out globally, our ambition is to zoom in, to take stock of and observe how transitions are enacted and how they unfold at various spatial scales, with different types of actor constellations, technologies and logics involved. As we zoom in, we also probe the work of transforming energy and transport systems as processes with wider implications than they would have had if the task was simply to replace light bulbs, generators, engines or energy carriers.

If Edison's trials had been conducted today, it would have been part of a broad movement, where social and technical configurations are actively "beta tested" in a limited way before being introduced to society at large (Marres 2020). Edison and his team conducted a small-scale trial under realistic conditions, which over the coming decades would be scaled up to provide blanket electricity coverage across nations and continents. Today, innovators, policy makers and research funders are actively pursuing and attempting to re-create similar dynamics within fields such as smart energy technology, renewable energy and electro mobility, through the establishment of pilot projects, test beds or demonstration projects. What such efforts entail and the effects of such projects are the key interests of this book.

Hargadon and Douglas (2001) noted that the effects of Edison's work in New York were not primarily technological, but institutional. Contemporary energy and transport projects are often made with the intention of testing how technology works in practice. In this book, however, we will make the point that such projects are always both social and technical: they do not only re-configure technological systems but also institutions, practices, everyday-life and politics. As the logics of piloting and pilot projects become more prevalent, such projects come to shape societies in new ways. Hence, the title of this book: Pilot Society and the Energy Transition, indicates that pilot projects have become one of the keyways through which societies are made and re-made. Such a perspective elevates the importance of innovation as an activity with far reaching consequences and opens for at least two types of questions. On the one hand, is the instrumental question of how such innovation can succeed. On the other hand, are questions of how such activities can be conducted in a fair, just and democratic way, promoting outcomes that not only reduce climate emissions but also produce just future societies. 


\section{Innovation And Politics Through Pilot and Demonstration Projects}

Our key focus in this book is a specific form of innovation that has risen in prominence as a way of responding to climate and sustainability challenges (Hughes et al. 2018; Castan Broto and Bulkeley 2013). As noted, this type of innovation is enacted through projects that might be referred to as pilot projects, demonstration projects, experiments or test beds. Given the diversity of such activities it is difficult to accurately quantify how prevalent they are, but Castan Broto and Bulkeley (2013) surveyed 627 projects of this type across 100 cities. In the following years, research and innovation funders such as the Horizon 2020 have increasingly emphasized the importance of this mode of working, which means there is no reason to believe that the trend is fading (see e.g. European Commission 2020).

Throughout this book, we use terms such as pilot projects, demonstrations and experiments as synonyms. Further, our interpretation of what constitutes a pilot is broad. For us, this term includes relatively small projects, as well as larger, targeted sets of projects and policies that set out to explicitly create new socio-technical realities within a demarcated site. An example of the latter is the Norwegian effort to become a pioneering society for electro mobility. This is not a pilot project in the traditional sense, but it is a concerted push within a geographically and socially limited area to produce conditions that materialize visions held by policy makers and stakeholders about how a future dominated by electromobility might look. In this way, the country is also frequently discussed as a "laboratory" for transport electrification. Our pragmatic use of these words echoes the diverse ways that they are used amongst practitioners in the fields we study. Further, it signals that our interest does not lie in establishing a finegrained typology of different activities, but rather more broadly, to explore a mode of innovation, which pits a set of ideas, technologies and principles of organizing innovative work against relatively realistic conditions and in what is often a public setting.

Coming from a background in Science and Technology Studies, the sorts of projects we discuss in this book can also be described as hybrids. Whereas scientific experiments have typically been conducted to learn about the character of the natural world, scientific demonstrations have been set-up to reveal such characteristics to a public audience (Latour 1983; Collins 1988). The sorts of projects discussed in this book as pilot 
projects, experiments or demo projects often do both. First, they intend to demonstrate to funders, commercial actors, researchers, governments and lay people, that some socio-technical configurations can work in real life and that they have desirable traits. Second, they often also seek to learn about how these socio-technical configurations interact with other elements in the world: how the configuration works in practice, how new technologies are used, what the consequences of new business models are, how the configuration interacts with different infrastructural systems and so on. Hence, pilot and demonstration projects often actively seek to produce a new reality, while at the same time studying the unfolding of this reality.

As hinted at, this means that the goals of such projects can be diverse. The goals are, however, often framed in terms of achieving quite specific technological goals (Marres 2018). Such technological goals can include testing and gaining practical experiences with the way new technologies work in (near to) real life conditions or investigating the complexities that might arise when several technologies are intended to work together. Other goals can be understood as to greater extent relate to social aspects of technology. Examples can include exploring how different actors understand or use technology or understanding why technologies are rejected. Projects can, for example, be rigged specifically for the purposes of generating social learning within an organization or amongst different actor groups, or to demonstrate or challenge what innovators consider to be flaws in current legislative and regulatory frameworks. At other times, such projects target the public, seeking to understand if emerging technologies, market structures and organizational forms are likely to be accepted, supported or even rejected.

We consider the development of pilot and demonstration projects to be a key strategy for enacting sustainability transitions in contemporary Europe and beyond, but we also believe that there is an untapped potential in doing such projects differently than they typically are today. While the paragraph above describes relatively conservative forms of innovation rooted in ideas of transforming society through implementing new technologies, there are also interesting examples of approaches that starts from a focus on social aspects. How can, for example, new energy technologies and new design practices be mobilized to produce new forms of communities (Martiskainen et al. 2018; Wilkie and Michael 2018)? In the following we will explore both how and why pilot projects are made, and consequences of carrying out these kinds of innovation projects once they 
are established. This means that we focus on the types of resources that are mobilized to make and shape such projects. Examples include European, national and local policies, a range of local issues, technologies and competence, as well as a diversity of actors.

Our focus on what demonstration and pilot projects do leads us to an interest in how they become part of broader societal transition processes. Such projects are seldom conducted without explicit ambitions of subsequent up-scaling, or of some form of transformative ambition that goes beyond the project as such (see e.g. Frantzeskaki et al. 2017; Naber et al. 2017; Ryghaug et al. 2019). If demonstration and pilot projects both formulate and materialize potential sustainable futures and succeed in transferring elements of such futures beyond their own immediate site and situation, they are important political entities that work to re-shape how key elements of contemporary and future societies are constituted. If societies indeed become pilot societies, such projects should be of major interest for social scientists, as sites that explicitly illustrate the constant making and re-making of society, hinting at potential directions and consequences before they are stabilized at a large scale.

Since we understand pilot and demonstration projects as political entities that are important for shaping the future not only for individual technologies but also, more broadly, for the societies that these technologies become part of, we are keen to explore the politics of such projects. An important aspect of this is the possibility that such projects might open for new modes of public participation in energy transition activities. On the one hand, we follow this question by enquiring into and against the backdrop of a quite common analysis that sees the implementation e.g. of smart energy technologies as a form of de-humanizing post-politics, or even anti-politics (Sadowski and Levenda 2020). Such analysis highlights that rapid technological change tends to result in the privatization of increasing aspects of societal decision making at the expense of traditional political institutions (e.g. Rosa 2013), and consequently that many technologies associated e.g. with the idea of smart energy or smart grids, limit the enactment of human agency in energy systems (Sadowski and Levanda 2020). On the other hand, we look into the potential for new modes of public participation in energy transition activities building on and being inspired by a body of literature that highlights the role of technologies and material objects in constituting issues and publics, and through this also enabling new forms of participation and new modes of democratic practice (e.g. Marres 2016). 
When new forms of participation emerge, we are interested in understanding how this participation comes about. As we inquire into this issue, we are inspired by literature that highlights how participation emerges as a relational phenomenon within wide ecologies of actors (Chilvers and Kearnes 2015; Chilvers et al. 2018). Such a perspective points to that pilot and demonstration projects are not only sites where citizens, organizations, companies and researchers can opt-in or opt-out of participation in organized transition-oriented activities. They are sites where participation is formatted or orchestrated through the work of other actors and through the mobilization of ideas about human agency, technologies, research and innovation practices and policies (Skjølsvold et al. 2018). We are particularly interested in how the participation of citizens is orchestrated in such projects. Conventionally, such projects have tended to cast participation of citizens in the form of acting as consumers, attempting to instigate individual behaviour change, or producing acceptance for new technologies (Chilvers et al. 2018).

In some instances, however, other and more material, political and issue-oriented forms of participation emerge (Throndsen and Ryghaug 2015; Martiskainen et al. 2018). An example of this can be found in projects that enable the enactment of what we call energy citizenship (Ryghaug et al. 2018). In such instances, the materiality of projects anchored, for example in technologies like solar panels and electric vehicles enables new political virtues on behalf of citizens (see also Szulecki 2018). Examples of such virtues include the formation of awareness, the formation of new knowledge and literacy as well as new modes of action and practices. These elements can be directed towards the enactment of political projects such as advancing energy transitions, mitigating climate change or promoting equity. In sum, our observations suggest that pilot projects can play an important role in enabling new and democratic forms of transition, but this is far from any predetermined outcome.

What we sketch out above indicates that our interest in pilot and demonstration projects is operationalized through a socio-technical understanding of the dynamics of innovation, politics and participation towards sustainability transitions. Our account here is rooted in concepts and ideas primarily from Science and Technology Studies (STS), but in the discussions that follow in this book, we also borrow insights from other strands of social scientific scholarship on energy and sustainability transitions. In what follows, we will first discuss the theoretical underpinnings of our 
work, before proceeding to highlight some of the key (socio-technical) traits of contemporary energy transitions relevant to discussions raised in this book.

\section{Sustainability Transitions: \\ A SOCIO-TECHNICAL BACKDROP}

The social sciences have always been concerned with understanding the relationship between social change and technological change. Johan Schot and Laur Kanger (2018) have argued that the last 250 years of industrialization and modernization can be described as a deep socio-technical transition, where the outcomes have been "increased labour productivity, mechanization, reliance on fossil fuels, resource-intensity, energy-intensity, and reliance on global value chains" (ibid., p. 1045). In light of such an interpretation of modernity we might read many of the classical social scientists such as Max Weber, Emile Durkheim, Georg Simmel and Karl Marx as primarily analysing social consequences of a long-term sociotechnical transition (see also Rosa 2013 for a related argument).

Over the last decades, an explicit focus on transitions has emerged as a social scientific way of engaging with the challenges of climate change and sustainability. Scholars have addressed such transitions from different perspectives. In this book we are particularly relating to those perspectives that explore the social and technical aspects of such transitions in tandem; in other words, those perspectives rooted in what we can call a sociotechnical understanding. Such perspectives have, on the one hand, been aimed at understanding the dynamics of transitions that have already unfolded in the past, while on the other hand, cultivating a normative and interventionist agenda aimed at understanding how to instigate contemporary and future transitions. In the following sections, we will first point to some of the dominant modes of such socio-technical analysis, before briefly outlining our own position.

\section{From Multi-level Perspectives to Symmetrical Understandings of the Social and Technical Processes of Sustainability Transitions}

In current academic discussions, the multi-level perspective (MLP) stands out as a particularly prominent framework for analysing sustainability transitions, with recent contributions in high profile journals like Science 
flagging ambitions far beyond any disciplinary boundaries (Geels et al. 2017). Building primarily on historical accounts (Geels 2002, 2005), the MLP makes a three-level conceptual distinction between niches, sociotechnical regimes and a landscape. The regime is arguably the key analytical concept of the MLP, as it represents a stable meso-level structure that contains the dominant "products and technologies, stocks of knowledge, user practices, expectations, norms, regulations etc" (Markard and Truffer 2008). Inspired by institutional theory, Geels (2004) posits that socio-technical regimes can be understood as a form of deep structure or grammar, or as a set of internally consistent rules that in evolutionary terms means that they are "Selection environment[s] for technological development in a certain field or sector, thus exerting a significant barrier for radical innovations to diffuse" (Markard and Truffer 2008).

Innovations can and do occur within socio-technical regimes. However, the literature highlights that such innovations tend to be incremental (e.g. Geels and Schot 2007), and hence insufficient in meeting current climate and sustainability challenges (Schot and Kanger 2018). Thus, through the lens of the MLP, sustainability transitions entail changing the character of existing regimes, or creating new regimes, mainly by way of creating radical breakthroughs of new niche technologies.

Analysed from a multi-level perspective, transitions emerge through interaction between the niche, regime and landscape level. Niches are the micro level and this is where scholars in this tradition typically identify radical innovations. For our purpose, niches are particularly interesting, since they have been highlighted as fertile soil for experimentation (e.g. Coenen et al. 2010). As part of this, pilot projects have been put forward as common elements in creating niche spaces (Raven et al. 2016). Niches tend to be organized as "protective spaces", which means that they serve to shield, nurture or empower new socio-technical configurations in order to strengthen their chances against the selection environment of established regimes (Smith and Raven 2012). Niches, then, tend to be described as smaller than regimes, and with rules that are less stable than those in regimes.

The macro landscape is largely seen as exogenous to the system. It is the "technical, physical and material backdrop that sustains society" (Geels and Schot 2007, p. 403). Change at this level is very slow, except for sudden shocks, such as wars, economic crises or pandemics. Despite this, landscapes change over time, and through this exert pressure on regimes. 
In sum, through the lens of the MLP one can say that transitions emerge through:

[...] External 'landscape' pressures (eg, climate change or cultural shifts) exerting pressure upon incumbent regimes (eg, the fossil-fuel based energy system) to open up 'windows of opportunity that might be filled by novel, radical innovations developed in 'niche' spaces (eg, renewable energy technologies). (Hargreaves et al. 2013, p. 403)

The journey of a new technology within such a scheme is often depicted as an s-curve, which tends to be described through four phases of transition (Rotmans et al. 2001). First, is a pre-development phase in which the status quo of socio-technical systems does not visibly change much. Second, is a take-off phase in which the state of the system begins to shift. Third, is an acceleration or breakthrough phase, where an accumulation of socio-cultural, economic, ecological and institutional changes react to each other, resulting in collective learning, diffusion and embedding of new technologies. Finally, a fourth phase, stabilization, is reached, and the speed of social change decreases. The journey is complete, and the niche technology has become part of an existing regime and thereby changes it, or a new regime is established. Studies using a multi-level perspective have tended to focus on the early phases of transitions, often in the form of experiments and pilot and demonstration projects. In this book we operate with a broader conceptualization, which renders experimentation visible also in later phases, and amongst actors who are not traditional niche actors.

As noted, the authors of this book come to the study of sustainability transitions from the perspective of Science and Technology studies (STS). The MLP, as discussed above, arguably represents a sort of synthesis of certain theoretical traditions within STS, and innovation studies (Hess and Sovacool 2020). On a generic level, STS as applied to energy studies “[...] is a research field that provides the capacity to see the interconnections, mutual shaping, co-constitution, or coproduction of the technical, social, and natural" (Hess and Sovacool 2020, p. 2). The MLP too, focuses on coconstruction, but mainly within micro-level niches where "technology, user preferences, regulation, symbolic meaning, infrastructure, and production systems" (Geels 2006) are co-constructed. Arguably, however, such coconstruction has not been a key focus within the MLP, which has been more concerned with the search for what Geels (2007) calls abstract 
patterns and explanatory mechanisms. Through this, the MLP has been flagged as having ambitions as "a middle-range theory", situated between grand theory and mundane practice (ibid.).

Hence, while theories are based on similar foundations and have much in common, there is also some tension between the MLP and STS in terms of analytical scope. Where STS-analysts have tended to focus on localized specificities of technology development, the MLP has tended to focus more on generic explanations. We believe that this divide does not only concern a division in how to account for stability and change, but more broadly, there are certain issues that tends to become back-grounded or even black-boxed within the MLP, in part, due to its quest for generic explanations of regime change. Examples are aspects of justice, controversies, practices, politics and power. In other words, while exploring fairly similar phenomena, MLP and STS scholars have tended to ask different questions: while the MLP focus more on the systemic aspects of technological innovation journeys, STS scholars have tended to be more interested in probing broader consequences of such journeys.

MLP scholars have engaged with the ontological and epistemological challenges arising from critique that has noted the relative absence of elements like practices and contestation. This has resulted in more refined models and efforts to shift focus and integrate new types of questions in MLP studies (e.g. Geels 2010a, 2011; Vasileiadou and Safarzyńska 2010). Nevertheless, there is still a certain style within MLP scholarship that favours a focus on innovation journeys: stories of how such journeys came about, and more recently, how to accelerate such innovation journeys (e.g. Roberts et al. 2018). We therefore firmly believe that STS have an important role in broadening and deepening the understanding of energy and sustainability transitions, beyond what is currently achieved through MLP and related innovation system focused approaches. To be more specific, while rooted in a socio-technical understanding of reality, studies within the MLP tend to have a techno-centric focus, centred around the introduction of new technologies, or the phasing out of old technologies.

While STS shares many of the same interests in the emergence of new technologies (e.g. Bijker et al. 1987), its focus is often distinctly different from that of MLP scholars. Within STS, there is, for example, a longstanding tradition of studying and normatively promoting processes of public engagement with science and technology (e.g. Wynne 1992; Jasanoff 2012; Chilvers and Kearnes 2015). Aspects such as inclusion, democratization and engagement is rarely made central within studies 
from the MLP, perhaps because such activities tends to slow down rather than speed up innovation processes (see e.g. Rosa 2013 for a discussion on the relationship between speed of innovation and democratic practice).

Endeavours of studying and advancing public engagement with and democratization of science and technology rest on the assumption that public engagement and participation can be resources for improving the quality of science and technology. Further, it also rests on the assumption that the highly specialized forms of expertise that typically produce cutting edge science and technology, is not always sensitive to the potentially wide societal implications of their own proposals. Finally, such endeavours rest on the assumption that producing and implementing new technologies do not only discretely impact specific sectors, regimes or industries but that they are also essential in shaping our societies more fundamentally.

Thus, while sharing a somewhat common ground when it comes to explaining stability or change as multi actor-processes that are constituted by the alignment of multiple simultaneous processes across society through social and technical means, STS narratives tend to focus attention elsewhere than most MLP-studies. Our ambition here is not to carve out an entire agenda for STS within the study of sustainability transitions, but rather to point briefly to three related trends that inspire us here; and we think STS offers particularly important insights that should be acknowledged and engaged with more broadly by transitions scholars and those interested in energy and sustainability transitions.

First, and most generically, critique from STS and related fields have arguably inspired a turn towards focusing on actors and the relations between actors and technologies in sustainability transition studies. Such critique has illustrated that the production of societal conditions that promote socio-technical novelty is not limited to niche activities. Instead, heterogeneous sets of actors, including incumbent actors, can work to produce social and technological innovation, and also the sites and spaces where technologies are intended to work (Åm 2015; Pallesen and Jenle 2018; Skjølsvold and Ryghaug 2020). Hence, different types of actors can become transition actors (Ryghaug et al. 2018; Sørensen et al. 2018). For us, considerations about the identification of transition actors, but also more abstract patterns of transition activity and agency will be important in discussions about how and why pilot and demonstration projects emerge, as well as in discussions about work to up-scale such pilots.

Second, and keeping with STS' focus on public engagement with science and technology, much work from STS-scholars on energy and 
sustainability transitions focus on the character of public participation in, engagement with and support for transitions. Technical and economic expertise involved in the production and implementation of new renewable energy technologies, have tended to see the public as a barrier to the successful implementation of their technologies (e.g. Barnett et al. 2012; Skjølsvold 2012; Eaton et al. 2017). STS scholars, on the other hand, have tended to highlight publics as potential resources of innovation (e.g. Lie and Sørensen 1996; Oudshoorn and Pinch 2003), who might contribute not only by accepting technologies alzssociated with the energy transition, but by shaping the roles of these technologies in society (Ryghaug et al. 2018; Skjølsvold et al. 2018; Throndsen et al. 2017). Hence, participation is a key phenomenon, both as an analytical category, and as a practical resource for realizing energy transition goals.

An important aspect here is that rather than seeing participation as the outcome of individual choice, STS-contributions tends to emphasize the collective production of conditions for participation (Chilvers and Longhurst 2016; Chilvers and Kearnes 2015; Skjølsvold et al. 2018). If innovators see the public as a barrier to implementation, they tend to produce a space where potential modes of participation are to accept and use technologies, or to reject and protest. Through a relational and coproductionist gaze, the responsibility of achieving an inclusive transition becomes distributed to more actors. Technologies can be designed to be inclusive and processes of organization can be conducted in inclusive ways. For us, understanding how such inclusivity can be achieved, and what stands in its way, is a central ambition.

Third and finally, the discussions above suggest that through mobilizing STS in discussions about energy transitions, one can gain a more symmetrical understanding of the social and technical processes of sustainability transitions. This would entail asking questions not only about how to change socio-technical systems, but also to ask more broadly about social aspects of sustainability transitions. On a basic level, social aspects and social categories have also become more prominent in transition studies based on MLP. Here, social categories, however, tends to be analysed directly in relationships to specific technologies. Examples include discussions about the role of technology users in energy transitions (Schot et al. 2016), or on different types of cultural repertoires (e.g. Swedish collectivism, Dutch consensus-based society, and the emphasis on individual freedoms that predominates in the UK) affects the speed of transition (Roberts et al. 2018). While we think such studies greatly enriches transition 
studies, they implicitly also run the risk of attributing the potential of change to technologies, while casting the social elements of societies as stable. Sustainability transitions, however, will require the transformation of both technology and society, which means that we cannot afford the privilege of stability to either one.

Thus, a focus on particular actors, objects and relations, opens the door to explore generic issues in a different way than through those studies based on typical multi-level understandings. To us, this means a keen interest in understanding changes within politics, lifestyles, cultures and understandings, in and of itself, and not foremost as residual categories that surround technological systems. STS-literatures opens for the analysis of how the social is produced (e.g. Latour 2005), or invented (Marres et al. 2018). Foregrounding the "social" of socio-technical might bring us closer to what Jasanoff (2018) has called "a humble approach to energy futures"-an approach that foregrounds society and issues such as justice, inclusion and equity together with ideas about which sort of societies we want to produce through innovation. We believe that the types of pilot and demonstration projects that we study in this book have significant potential to contribute to such an agenda, but that they currently do so in a relatively limited way. Hence, our contribution here should be read as constructive criticism, which seeks to expand on the logics of contemporary innovation in the name of sustainability.

In what follows, we will shift focus from theory to practice and sketch some key developments within the empirical field we engage with in this book.

\section{The Empirical Field: A Brief Look on Trends AND DeVElopments}

Considering the climate and sustainability challenges the planet is facing, there is a need to curb emissions from across sectors drastically, and quickly. On the one hand, this entails replacing the carbon-intensive ways that energy is produced for example, from oil, gas and coal to solar-, windand bio-energy. On the other hand, it entails changing the way energy is used for example, reducing energy consumption and improving energy efficiency. In other words, there is a need for drastic changes in what has traditionally been described as the production- and the demand-side of energy systems. 
Over the last 10 years the developments on the production side of this equation has arguably accelerated drastically. We have seen unprecedented levels of solar and wind power being installed and delivered to the grid; a trend that most actors believe will continue (e.g. IEA 2019). Hence, if we return to the earlier discussed phases of sustainability transitions (Rotmans et al. 2001), many technologies are currently in a phase of acceleration. What does this acceleration entail in practice, and why has piloting and demonstration projects become so central in this period?

A few things are worth noting in relation to these questions. First, renewable energy production sites tend to be smaller than traditional fossil fuel power plants. They are also typically much more distributed throughout the electricity grid-electricity is no longer only generated in a few, large scale facilities, but rather at a range of different sites and scales. A quite common trait, then, is that energy is produced much closer to where energy is consumed. A solar panel can be located on your roof, a wind turbine can be on or close to your own property.

These changes, however, do not only concern size and proximity to production facilities, they also imply changes in the character of energy supply, which becomes more variable with increasing shares of renewable energy technologies. Fossil based power plants can deliver stable electricity loads $24 / 7$, while the production of electricity from sun and wind is volatile and varies with season, time of day and weather. Hence, there is not necessarily a good match between when electricity is produced and when it is in demand. This coincides with another trend in energy systems across Europe, namely that an increasing share of services such as heating, cooling and transportation gradually is becoming electrified. This means that we have a situation where electricity production becomes more variable, while electricity demand is increasing.

These new dynamics clearly illustrates the socio-technical character of the current transition. To succeed in transforming our energy systems in a more sustainable direction, it is not enough to implement new renewable energy technologies, or even to ensure that this happens while coal and other fossil fuels are phased out. The task at hand is a balancing act which involves changing how millions of actors across Europe and beyond, use and relate to electricity on a daily basis. A key term often mobilized to describe this need for a new type of dynamics is demand side flexibility. Demand side flexibility entails that actors such as households, small businesses and industry actors should agree to shift some of their electricity demand to periods with less demand to avoid grid congestion problems, 
to avoid investments towards increasing the capacity of current electricity grids and to facilitate the implementation of variable renewables (e.g. Friis and Christensen 2016).

Currently, many actors hope that smart grids and smart energy technologies will serve as technological enablers of such flexibility (e.g. Torriti 2020), and many of the pilot and demonstration projects we explore in this book come from this domain. Making the grid "smart" entails augmenting energy systems with software, sensors and other ICT technologies, which can enable new forms of communication between actors in the energy system, new pricing schemes and the automation of certain actions (e.g. Silvast et al. 2018; Skjølsvold et al. 2015). Demand response technologies and services are a key element of the smart grid, typically seeking to influence the timing and intensity of energy demand. Common examples include time of use (TOU) tariffs, critical peak pricing, feedback technologies and automated demand controllers (Ingeborgrud et al. 2020; Torriti 2015). Adding complexity to these discussions are new technological developments for instance within battery technology, that suggests batteries from electric vehicles or stand-alone batteries might play an increasingly important role in providing flexibility (see e.g. Noel et al. 2019).

Another characteristic of the developments we have sketched above, is that the technological changes are accompanied by changes in the roles of actors that are involved in the system, or the emergence of entirely new roles. New actors are producing energy: prosumers, energy cooperatives and new types of companies. ICT actors increasingly find opportunities in the smart energy field. New types of business emerge, such as those that specialize in aggregating the flexibility e.g. from fleets of electric vehicles. Many have predicted that the energy industry will see a wave of disruption in which the logic of incumbent infrastructures and industries are replaced by new business models and new forms of organization around the production and distribution of electricity (e.g. Parag and Sovacool 2016). Others point out that the future not only holds new technologies and new roles, but that the character of the very systems might change drastically, for example, becoming microgrids where energy is managed as a common pool resource (Wolsink 2012).

The discussions above point to some developments within energy systems and those should be recognizable throughout Europe and beyond. They also illustrate a generic challenge of energy transitions, which points towards the centrality of the types of projects that we explore in this book. 
As energy transitions powered by variable renewable energy production and increasing electrification unfold, analytical and practical complexity increases (Turnheim et al. 2018). Potential roles change, practices change, sectors are coupled in new and sometimes surprising ways, new business models and modes of organization emerge and price structures change. The effects of all these simultaneous changes are difficult to assess even if one only focuses on technologies and looks at the energy system in isolation. Zooming out to contemplate how all of these changes might feed into broader societal processes, it soon becomes clear that we are dealing with a set of open ended and potentially wicked problems (e.g. Buchanan 1992) and as such, many actors see the need to try out and test elements of such ecosystems in localized settings.

These complexities are parts of the backdrop for the current interest in pilot and demonstration projects amongst innovators, policy makers and systems designers. This complexity is also what sparks our interest as researchers. On the one hand, our interest here is fuelled by a curiosity about what it takes to make such socio-technical configurations 'work' in practice. On the other hand, our background in STS and energy social science, allows us to take this interest beyond asking how pilot projects may support and shape technology-oriented innovation and to focus more deeply on how pilot and demonstration projects are made, what their societal and political consequences are, and whether they cater for democratic participation or not. The remainder of this book will be dedicated to these questions.

\section{REFERENCES}

$\AA ̊ m$, H. (2015). The sun also rises in Norway: Solar scientists as transition actors. Environmental Innovation and Societal Transitions, 16, 142-153.

Barnett, J., Burningham, K., Walker, G., \& Cass, N. (2012). Imagined publics and engagement around renewable energy technologies in the UK. Public Understanding of Science, 21(1), 36-50.

Bijker, W. E., Hughes, T. P., \& Pinch, T. J. (Eds.). (1987). The social construction of technological systems: New directions in the sociology and history of technology. MIT Press.

Broto, V. C., \& Bulkeley, H. (2013). Maintaining climate change experiments: Urban political ecology and the everyday reconfiguration of urban infrastructure. International Journal of Urban and Regional Research, 37(6), 1934-1948.

Buchanan, R. (1992). Wicked problems in design thinking. Design Issues, $8(2), 5-21$. 
Chilvers, J., \& Kearnes, M. (Eds.). (2015). Remaking participation: Science, environment and emergent publics. Routledge.

Chilvers, J., \& Longhurst, N. (2016). Participation in transition (s): Reconceiving public engagements in energy transitions as co-produced, emergent and diverse. Journal of Environmental Policy \& Planning, 18(5), 585-607.

Chilvers, J., Pallett, H., \& Hargreaves, T. (2018). Ecologies of participation in socio-technical change: The case of energy system transitions. Energy Research \& Social Science, 42, 199-210.

Coenen, L., Raven, R., \& Verbong, G. (2010). Local niche experimentation in energy transitions: A theoretical and empirical exploration of proximity advantages and disadvantages. Technology in Society, 32(4), 295-302.

Collins, H. M. (1988). Public experiments and displays of virtuosity: The core-set revisited. Social Studies of Science, 18(4), 725-748.

Eaton, W. M., Burnham, M., Hinrichs, C. C., \& Selfa, T. (2017). Bioenergy experts and their imagined "obligatory publics" in the United States: Implications for public engagement and participation. Energy Research \& Social Science, 25, 65-75.

European Commission. (2020). Horizon 2020. Work Programme. Brussels. Accessed from: https://ec.europa.eu/research/participants/data/ref/ h2020/wp/2018-2020/main/h2020-wp1820-intro_en.pdf

Frantzeskaki, N., Borgström, S., Gorissen, L., Egermann, M., \& Ehnert, F. (2017). Nature-based solutions accelerating urban sustainability transitions in cities: Lessons from Dresden, Genk and Stockholm cities. In Nature-based solutions to climate change adaptation in urban areas (pp. 65-88). Cham: Springer.

Friis, F., \& Christensen, T. H. (2016). The challenge of time shifting energy demand practices: Insights from Denmark. Energy Research \& Social Science, $19,124-133$.

Geels, F. W. (2002). Technological transitions as evolutionary reconfiguration processes: A multi-level perspective and a case-study. Research Policy, 31(8-9), 1257-1274.

Geels, F. W. (2004). From sectoral systems of innovation to socio-technical systems: Insights about dynamics and change from sociology and institutional theory. Research Policy, 33(6-7), 897-920.

Geels, F. W. (2005). The dynamics of transitions in socio-technical systems: A multi-level analysis of the transition pathway from horse-drawn carriages to automobiles (1860-1930). Technology Analysis \& Strategic Management, $17(4), 445-476$.

Geels, F. W. (2006). Co-evolutionary and multi-level dynamics in transitions: The transformation of aviation systems and the shift from propeller to turbojet (1930-1970). Technovation, 26(9), 999-1016. 
Geels, F. W. (2007). Feelings of discontent and the promise of middle range theory for STS: Examples from technology dynamics. Science, Technology, \& Human Values, 32(6), 627-651.

Geels, F. W. (2010a). The role of cities in technological transitions: Analytical clarifications and historical examples. In H. Bulkeley, V. Castan Broto, M. Hodson, \& S. Marvin (Eds.), Cities and low carbon transitions (pp. 29-44). Routledge.

Geels, F. W. (2011). The multi-level perspective on sustainability transitions: Responses to seven criticisms. Environmental Innovation and Societal Transitions, $1(1), 24-40$.

Geels, F. W., \& Schot, J. (2007). Typology of sociotechnical transition pathways. Research Policy, 36(3), 399-417.

Geels, F. W., Sovacool, B. K., Schwanen, T., \& Sorrell, S. (2017). Sociotechnical transitions for deep decarbonization. Science, 357(6357), 1242-1244.

Hargadon, A. B., \& Douglas, Y. (2001). When innovations meet institutions: Edison and the design of the electric light. Administrative Science Quarterly, $46(3), 476-501$.

Hargreaves, T., Longhurst, N., \& Seyfang, G. (2013). Up, down, round and round: Connecting regimes and practices in innovation for sustainability. Environment and Planning A, 45(2), 402-420.

Hess, D. J., \& Sovacool, B. K. (2020). Sociotechnical matters: Reviewing and integrating science and technology studies with energy social science. Energy Research o Social Science, 65, 101462.

Hughes, T. P. (1993). Networks of power: Electrification in Western society, 1880-1930. JHU Press.

Hughes, S., Chu, E. K., \& Mason, S. G. (2018). Climate change in cities. Cham: Springer.

IEA. (2019). Renewables 2019, IEA, Paris. Retrieved from https://www.iea.org/ reports/renewables-2019

Ingeborgrud, L., Heidenreich, S., Ryghaug, M., Skjølsvold, T. M., Foulds, C., Robison, R., ... Mourik, R. (2020). Expanding the scope and implications of energy research: A guide to key themes and concepts from the Social Sciences and Humanities. Energy Research \& Social Science, 63, 101398.

Jasanoff, S. (2012). Science and public reason. Routledge.

Jasanoff, S. (2018). Just transitions: A humble approach to global energy futures. Energy Research \& Social Science, 35, 11-14.

Latour, B. (1983). Give me a laboratory and I will raise the world. In K. KnorrCetina \& M. Mulkay (Eds.), Science observed: Perspectives on the social study of science (pp. 141-170). London: Sage.

Latour, B. (2005). From realpolitik to dingpolitik. In Making things public: Atmospheres of democracy (p. 1444). MIT Press. 
Lie, M., \& Sørensen, K. H. (Eds.). (1996). Making technology our own?: Domesticating technology into everyday life. Scandinavian University Press North America.

Markard, J., \& Truffer, B. (2008). Technological innovation systems and the multi-level perspective: Towards an integrated framework. Research Policy, $37(4), 596-615$.

Marres, N. (2016). Material participation: Technology, the environment and everyday publics. Springer.

Marres, N. (2018). What if nothing happens? Street trials of intelligent cars as experiments in participation. In TechnoScience in society, sociology of knowledge yearbook (pp. 1-20). Nijmegen: Springer/Kluwer.

Marres, N. (2020). What if nothing happens? Street trials of intelligent cars as experiments in participation. In TechnoScienceSociety (pp. 111-130). Cham: Springer, Chicago.

Marres, N., Guggenheim, M., \& Wilkie, A. (2018). Inventing the social. Manchester: Mattering Press.

Martiskainen, M., Heiskanen, E., \& Speciale, G. (2018). Community energy initiatives to alleviate fuel poverty: The material politics of Energy Cafés. Local Environment, 23(1), 20-35.

Naber, R., Raven, R., Kouw, M., \& Dassen, T. (2017). Scaling up sustainable energy innovations. Energy Policy, 110, 342-354.

Noel, L., Rubens, d., G. Z., Kester, J., \& Sovacool, B. K. (2019). Vehicle-to-grid: A Sociotechnical transition beyond electric mobility. Springer.

Oudshoorn, N. E., \& Pinch, T. (2003). How users matter: The co-construction of users and technologies. MIT Press.

Pallesen, T., \& Jenle, R. P. (2018). Organizing consumers for a decarbonized electricity system: calculative agencies and user scripts in a Danish demonstration project. Energy Research \& Social Science, 38, 102-109.

Parag, Y., \& Sovacool, B. K. (2016). Electricity market design for the prosumer era. Nature Energy, 1(4), 1-6.

Raven, R., Kern, F., Verhees, B., \& Smith, A. (2016). Niche construction and empowerment through socio-political work. A meta-analysis of six low-carbon technology cases. Environmental Innovation and Societal Transitions, $18,164-180$.

Roberts, C., Geels, F. W., Lockwood, M., Newell, P., Schmitz, H., Turnheim, B., \& Jordan, A. (2018). The politics of accelerating low-carbon transitions: Towards a new research agenda. Energy Research \& Social Science, 44, 304-311. Rogelj, J., Shindell, D., Jiang, K., Fifita, S., Forster, P., Ginzburg, V. ... Vilariño, M. V. (2018). Mitigation pathways compatible with $1.5^{\circ} \mathrm{C}$ in the context of sustainable development. In: Global Warming of $1.5^{\circ} \mathrm{C}$. An IPCC Special Report on the impacts of global warming of $1.5^{\circ} \mathrm{C}$ above pre-industrial levels and related global greenhouse gas emission pathways, in the context of strengthening the 
global response to the threat of climate change, sustainable development, and efforts to eradicate poverty. Retrieved May 26, 2020, from https://www.ipcc. ch/site/assets/uploads/sites/2/2019/02/SR15_Chapter2_Low_Res.pdf

Rosa, H. (2013). Social acceleration: A new theory of modernity. Columbia University Press.

Rotmans, J., Kemp, R., \& Van Asselt, M. (2001). More evolution than revolution: Transition management in public policy. Foresight-The Journal of Future Studies, Strategic Thinking and Policy, 3(1), 15-31.

Ryghaug, M., Ornetzeder, M., Skjølsvold, T. M., \& Throndsen, W. (2019). The role of experiments and demonstration projects in efforts of upscaling: an analysis of two projects attempting to reconfigure production and consumption in energy and mobility. Sustainability, $11(20), 5771$.

Ryghaug, M., Skjølsvold, T. M., \& Heidenreich, S. (2018). Creating energy citizenship through material participation. Social Studies of Science, 48(2), 283-303.

Sadowski, J., \& Levenda, A. M. (2020). The anti-politics of smart energy regimes. Political Geography, 81, 102202.

Schot, J., \& Kanger, L. (2018). Deep transitions: Emergence, acceleration, stabilization and directionality. Research Policy, 47(6), 1045-1059.

Schot, J., Kanger, L., \& Verbong, G. (2016). The roles of users in shaping transitions to new energy systems. Nature Energy, 1(5), 1-7.

Silvast, A., Williams, R., Hyysalo, S., Rommetveit, K., \& Raab, C. (2018). Who 'uses' smart grids? The evolving nature of user representations in layered infrastructures. Sustainability, 10(10), 3738.

Skjølsvold, T. M. (2012). Publics in the pipeline. In N. Möllers \& K. Zachmann (Eds.), Past and present energy societies. Bielefeld: Transcript Verlag.

Skjølsvold, T. M., \& Ryghaug, M. (2020). Temporal echoes and cross-geography policy effects: Multiple levels of transition governance and the electric vehicle breakthrough. Environmental Innovation and Societal Transitions, 35, 232-240.

Skjølsvold, T. M., Ryghaug, M., \& Berker, T. (2015). A traveler's guide to smart grids and the social sciences. Energy Research of Social Science, 9, 1-8.

Skjølsvold, T. M., Throndsen, W., Ryghaug, M., Fjellså, I. F., \& Koksvik, G. H. (2018). Orchestrating households as collectives of participation in the distributed energy transition: New empirical and conceptual insights. Energy Research \& Social Science, 46, 252-261.

Smith, A., \& Raven, R. (2012). What is protective space? Reconsidering niches in transitions to sustainability. Research Policy, 41(6), 1025-1036.

Sørensen, K. H., Lagesen, V. A., \& Hojem, T. S. M. (2018). Articulations of mundane transition work among consulting engineers. Environmental Innovation and Societal Transitions, 28, 70-78.

Szulecki, K. (2018). Conceptualizing energy democracy. Environmental Politics, 27(1), 21-4l. 
Throndsen, W., \& Ryghaug, M. (2015). Material participation and the smart grid: Exploring different modes of articulation. Energy Research \& Social Science, $9,157-165$.

Throndsen, W., Skjølsvold, T. M., Ryghaug, M., \& Christensen, T. H. (2017). From consumer to prosumer. Enrolling users into a Norwegian PV pilot. ECEEE Summer Study Proceedings, 2017.

Torriti, J. (2015). Peak energy demand and demand side response. Chicago: Routledge.

Torriti, J. (2020). Appraising the economics of smart meters: Costs and benefits. Routledge.

Turnheim, B., Wesseling, J., Truffer, B., Rohracher, H., Carvalho, L., \& Binder, C. (2018). Challenges ahead: Understanding, assessing, anticipating and governing foreseeable societal tensions to support accelerated low-carbon transitions in Europe. In Advancing energy policy (pp. 145-161). Cham: Palgrave Pivot.

Vasileiadou, E., \& Safarzyńska, K. (2010). Transitions: Taking complexity seriously. Futures, 42(10), 1176-1186.

Wilkie, A., \& Michael, M. (2018). Designing and doing: Enacting energy-andcommunity. In N. Marres, M. Guggenheim, \& A. Wilkie (Eds.), Inventing the social (pp. 125-148). Manchester: Mattering Press.

Wolsink, M. (2012). The research agenda on social acceptance of distributed generation in smart grids: Renewable as common pool resources. Renewable and Sustainable Energy Reviews, 16(1), 822-835.

Wynne, B. (1992). Misunderstood misunderstanding: Social identities and public uptake of science. Public Understanding of Science, 1(3), 281-304.

Open Access This chapter is licensed under the terms of the Creative Commons Attribution 4.0 International License (http://creativecommons.org/licenses/ by $/ 4.0 /$ ), which permits use, sharing, adaptation, distribution and reproduction in any medium or format, as long as you give appropriate credit to the original author(s) and the source, provide a link to the Creative Commons licence and indicate if changes were made.

The images or other third party material in this chapter are included in the chapter's Creative Commons licence, unless indicated otherwise in a credit line to the material. If material is not included in the chapter's Creative Commons licence and your intended use is not permitted by statutory regulation or exceeds the permitted use, you will need to obtain permission directly from the copyright holder.

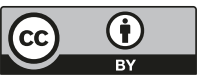

